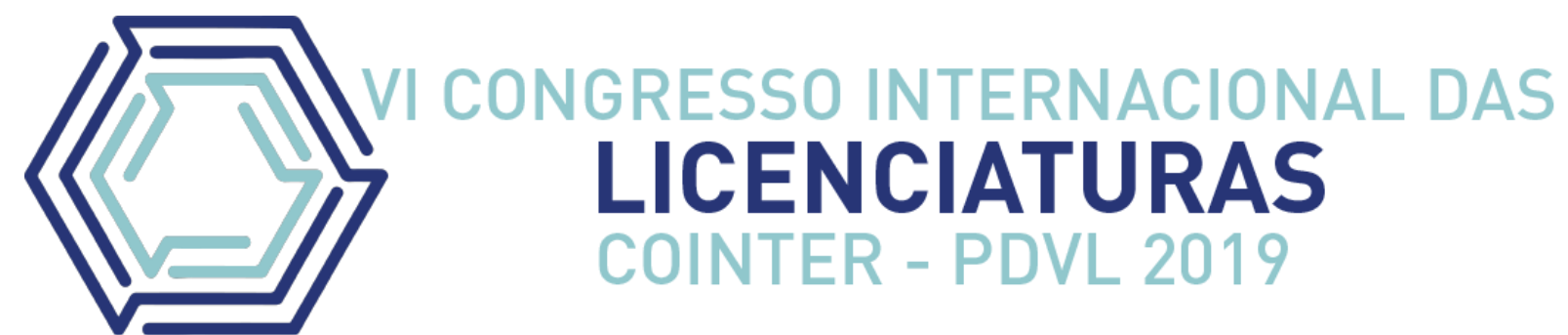

\title{
A PRÁTICA PEDAGÓGICA NOS ANOS INICIAIS DO ENSINO FUNDAMENTAL: DESAFIOS PARA A FORMAÇÃO DOCENTE
}

\section{LA PRÁCTICA PEDAGÓGICA EN LOS PRIMEROS AÑOS DE EDUCACIÓN: DESAFÍOS PARA LA EDUCACIÓN DE PROFESORES}

\section{THE PEDAGOGICAL PRACTICE IN THE EARLY YEARS OF EDUCATION: CHALLENGES FOR TEACHER EDUCATION}

\author{
Apresentação: Comunicação Oral \\ Jeisy da Silva Melo ${ }^{1}$; Anderson Fernandes de Alencar $^{2}$ \\ DOI: https://doi.org/10.31692/2358-9728.VICOINTERPDVL.2019.0095
}

\begin{abstract}
Resumo
Este artigo apresenta um recorte dos resultados das atividades realizadas no Programa de Iniciação Científica Voluntária (PIC) no período de outubro de 2018 até o final de junho 2019, no projeto intitulado "A prática pedagógica nos anos iniciais do ensino fundamental: desafios para a formação docente." A pesquisa tem como objetivo geral analisar as percepções de profissionais da educação do município de Garanhuns (PE) acerca da formação inicial em Curso de Licenciatura em Pedagogia para a prática pedagógica nos anos iniciais do ensino fundamental. Os autores utilizados para embasar esse artigo foram Freire (1987, 1991, 1996), Iskandar e Leal (2002), Libâneo e Garrido (1999), Nóvoa (2009), Pimenta (1997), Sommerhalder et al (2016), Souza et al (2016) e Tardif (2010). Foi realizada uma pesquisa exploratória (APPOLINÁRIO, 2011) com abordagem qualitativa e quantitativa (SEVERINO, 2007). A forma de coleta de dados foi o questionário (SEVERINO, 2007). Em relação a formação inicial, os resultados mostram que os cursos de graduação ofertados contribuíram para a formação dos professores, tendo sidos positivos para os docentes mediante suas respostas. Porém estes têm deixado várias lacunas formativas principalmente no que diz respeito a prática, este foi o ponto mais enfatizado pelos professores em suas respostas, o preparo para o exercício da prática em sala de aula ainda é um ponto frágil dos cursos de formação. A maioria dos professores aponta que é foi no exercício diário da profissão que aprende a prática.
\end{abstract}

Palavras-Chave: Formação Inicial; Pedagogia; Ensino Fundamental; Prática docente.

\section{Resumen}

Este artículo presenta un resumen de los resultados de las actividades realizadas en el Programa Voluntario de Iniciación Científica (PIC) desde octubre de 2018 hasta finales de junio de 2019, en el proyecto titulado "Práctica pedagógica en los primeros años de la escuela primaria:

1 Graduanda em Licenciatura em Pedagogia, UFRPE/UAG, jeisymelo1 @ gmail.com

2 Doutor em Educação, UFRPE/UAG, anderson.alencar@gmail.com 
desafíos para la capacitación. La investigación tiene como objetivo analizar las percepciones de los profesionales de la educación del municipio de Garanhuns (PE) sobre la capacitación inicial en un curso de pedagogía para la práctica pedagógica en los primeros años de la escuela primaria. Los autores que apoyaron teóricamente este artículo fueron Freire (1987, 1991, 1996), Iskandar y Leal (2002), Libane y Garrido (1999), Nóvoa (2009), Pimenta (1997), Sommerhalder et al (2016), Souza et al (2016) y Tardif (2010). Se realizó una investigación exploratoria (APPOLINÁRIO, 2011) con enfoque cualitativo y cuantitativo (SEVERINO, 2007). La forma de recopilación de datos fue el cuestionario (SEVERINO, 2007). Con respecto a la educación inicial, los resultados muestran que los cursos de pregrado ofrecidos contribuyeron a la formación de docentes, habiendo sido positivos para los docentes a través de sus respuestas. Sin embargo, estos han dejado varias brechas formativas, especialmente con respecto a la práctica, este fue el punto más enfatizado por los maestros en sus respuestas, la preparación para la práctica de la práctica en el aula sigue siendo un punto débil de los cursos de capacitación. La mayoría de los maestros señalan que es el ejercicio diario de la profesión lo que aprende la práctica

Palabras Clave: Formación inicial; Pedagogía; Enseñanza fundamental; Práctica docente.

\begin{abstract}
This article presents a summary of the results of activities carried out in the Voluntary Scientific Initiation Program (PIC) from October 2018 until the end of June 2019, in the project entitled "Pedagogical practice in the early years of elementary school: challenges for training The research aims to analyze the perceptions of education professionals from the municipality of Garanhuns (PE) about the initial training in a Pedagogy Degree Course for pedagogical practice in the early years of elementary school. The authors used to theoretically support this article were Freire (1987, 1991, 1996), Iskandar and Leal (2002), Libâneo and Garrido (1999), Nóvoa (2009), Pimenta (1997), Sommerhalder et al (2016), Souza et al (2016) and Tardif (2010). An exploratory research was performed (APPOLINÁRIO, 2011) with qualitative and quantitative approach (SEVERINO, 2007). The form of data collection was the questionnaire (SEVERINO, 2007). Regarding initial education, the results show that the undergraduate courses offered contributed to the formation of teachers, having been positive for teachers through their responses. However, these have left several formative gaps, especially regarding the practice, this was the point most emphasized by the teachers in their answers, the preparation for the practice of classroom practice is still a weak point of the training courses. Most teachers point out that it is the daily exercise of the profession that learns the practice.
\end{abstract}

Keywords: Initial formation; Pedagogy; Elementary School; Teaching practice.

\title{
Introdução
}

O estágio atual da organização social em que nos encontramos, entendida como sociedade da informação por uns, e como sociedade do conhecimento por outros, tem demandado dos profissionais das mais diversas áreas uma postura investigativa, proativa, crítica e reflexiva diante da informação e do conhecimento. Não tem se concebido mais um profissional restrito exclusivamente ao que lhe foi ensinado na universidade.

A universidade, por sua vez, se vê desafiada a manter-se atualizada em conteúdos, 
metodologias e estratégias didáticas para dar conta do novo cenário em que o conhecimento se encontra, assim como dos novos perfis de estudantes que adentram aos espaços formativos. $\mathrm{Na}$ velocidade com que se produz e se dissemina a informação, o profissional que concluiu seu curso na universidade depois de quatro, cinco ou seis anos, já está “desatualizado".

Esses desafios, contudo, não se restringem a universidade, mas são vivenciados nos diversos níveis e modalidades da educação nacional. O (A) estudante do século XXI, como é comum perceber na universidade e reiteradamente nas falas dos colegas que atuam na educação básica, não se contentam mais com a escuta passiva e silenciosa de conteúdos "depositados" por um professor que acredita "saber tudo" (FREIRE, 1987). Primeiro que, o professor "sabe tudo" nunca existiu e nunca existirá devido à multiplicidade de informações e conhecimentos disponíveis em sua área de atuação / formação, e disponíveis em diversas línguas, desconhecidas ao pesquisador. E, segundo, porque o estudante tem acesso amplo a informação que lhe poderia "depositar" o professor conteudista. Estas questões, entre outras, demandam novos(as) professores(as) a "altura do seu tempo", assim como universidades que acompanhem reflexivamente o seu tempo histórico.

Diante deste cenário, órgãos do Estado, como o Ministério da Educação, as universidades e faculdades públicas e privadas nos cursos de licenciatura em Pedagogia e demais licenciaturas, se veem diante da necessidade de manter seu projeto pedagógico e matrizes curriculares atualizadas, buscando atender as exigências da Educação Básica e as especificidades sociais, econômicas, culturais e educacionais de cada contexto em que estes profissionais estão inseridos. Cursos de licenciatura, vale salientar, também regidos pelas orientações e normativas próprias dos órgãos deliberativos do próprio Estado, como as Diretrizes Curriculares Nacionais (2006) sob a forma de resoluções.

Nesta direção, este artigo apresenta um recorte dos resultados das atividades realizadas no Programa de Iniciação Científica Voluntária (PIC) no período de agosto de 2018 até o final de julho de 2019, no projeto de pesquisa intitulado "A prática pedagógica nos anos iniciais do ensino fundamental: desafios para a formação docente", tendo este por objetivo analisar as percepções de profissionais da educação do município de Garanhuns (PE) acerca da formação inicial em Curso de Licenciatura em Pedagogia para atuação nos anos iniciais do ensino fundamental.

Com este trabalho pretende-se contribuir para a ampliação do campo de pesquisas relativas à formação docente e mais especificamente em relação aos cursos de Licenciatura em 
Pedagogia, bem como a reflexão a respeito da prática docente no ensino fundamental mediante a formação inicial.

\title{
Fundamentação teórica
}

Formar professores para o exercício da prática pedagógica é um desafio. A profissão do pedagogo desde do início de sua concepção, é afetada pela desvalorização, bem como pelas mudanças históricas, políticas e sociais ao longo do tempo, que afetaram a educação e os pedagogos.

Selma Garrido Pimenta, pesquisadora que tem se dedicado a investigar os processos de formação de professores (as), em diversos de seus textos e livros, tem insistido que a formação efetiva destes profissionais só acontecerá quando os conteúdos a serem refletidos forem respostas aos desafios impostos pela prática, criticando o distanciamento entre escola e universidade, bem como a dicotomia entre teoria e prática. Em seu artigo "Formação de Professores - Saberes da Docência e Identidade do Professor", problematiza o modelo de formação inicial e continuada empreendida comumente:

\begin{abstract}
Em relação à formação inicial, pesquisas (Piconez, 1991; Pimenta, 1994; Leite, 1994) têm demonstrado que os cursos de formação, ao desenvolverem um currículo formal com conteúdos e atividades de estágios, distanciados da realidade das escolas, numa perspectiva burocrática e cartorial que não dá conta de captar as contradições presentes na prática social de educar, pouco têm contribuído para gestar uma nova identidade do profissional docente [...] No que se refere à formação contínua, a prática mais freqüente tem sido a de realizar cursos de suplência e/ou atualização dos conteúdos de ensino. Esses programas têm se mostrado pouco eficientes para alterar a prática docente e, consequentemente, as situações de fracasso escolar, por não tomarem a prática docente e pedagógica escolar nos seus contextos. Ao não colocá-las, como o ponto de partida e o de chegada da formação, acabam por, tão somente, ilustrar individualmente o professor, não lhe possibilitando articular e traduzir os novos saberes em novas práticas (PIMENTA, 1997, p. 5-6).
\end{abstract}

Em direção similar, Maurice Tardif, em diversas de suas obras, mas especialmente no seu livro "Saberes docentes e formação profissional" defende que a consolidação do saber docente, e na sequência, de sua prática docente, se dá na confluência dinâmica entre uma série de saberes diversos que chamou de "disciplinares, curriculares, profissionais (incluindo os das ciências da educação e da pedagogia), pedagógicos e experienciais ou práticos”. E explica:

Pode-se chamar de saberes profissionais o conjunto de saberes transmitidos pelas instituições de formação de professores (escolas normais ou faculdades de ciências da educação) [...] Os saberes pedagógicos apresentam-se como doutrinas 
ou concepções provenientes de reflexões sobre a prática educativa no sentido amplo do termo, reflexões racionais e normativas que conduzem a sistemas mais ou menos coerentes de representação e de orientação da atividade educativa [...] Os saberes disciplinares: são saberes sociais definidos e selecionados pela instituição universitária. Estes saberes integram-se igualmente à prática docente através da formação (inicial e contínua) dos professores nas diversas disciplinas oferecidas pela universidade [...] Os saberes curriculares: correspondem aos discursos, objetivos, conteúdos e métodos a partir dos quais a instituição escolar categoriza e apresenta os saberes sociais por ela definidos e selecionados como modelos da cultura erudita e de formação para a cultura erudita [...] Os saberes experienciais: conjunto de saberes atualizados, adquiridos e necessários no âmbito da prática da profissão docente e que não provêm das instituições de formação nem dos currículos (TARDIF, 2012, p. 36-39).

Por fim, citamos Paulo Freire que, em sua trajetória pessoal e profissional, sempre esteve preocupado com a formação de professores. Essa preocupação toma corpo com os processos formativos dos monitores na experiência conhecida pelas " $40 \mathrm{~h}$ de Angicos", será uma constante no Plano Nacional de Alfabetização (1963) e nas atividades que desenvolveu no Chile, na África e no seu regresso ao Brasil, na Unicamp, PUC-SP e USP.

Em sua produção intelectual, Freire insistia em dizer que não nascemos educadores, mas nos fazemos educadores na vivência da prática e de sua reflexão sobre esta. Em suas próprias palavras, afirma:

Ninguém começa a ser educador numa certa terça-feira às quatro horas da tarde. Ninguém nasce educador ou marcado para ser educador. A gente se faz educador, a gente se forma, como educador, permanentemente, na prática e na reflexão sobre a prática (FREIRE, 1991, p. 32).

O educador esteve tão preocupado com a formação dos professores que dedica a sua última obra, publicada enquanto vivo, a Pedagogia da Autonomia, a esse tema, dando-lhe por subtítulo "saberes necessários a prática educativa", reiterando em diversas ocasiões nesta publicação, a importância de refletir a prática, buscando a sua permanente reinvenção.

\footnotetext{
Por isso é que, na formação permanente dos professores, o momento fundamental é o da reflexão crítica sobre a prática. É pensando criticamente a prática de ontem que se pode melhorar a próxima prática. O próprio discurso teórico, necessário à reflexão crítica, tem de ser de tal modo concreto que quase se confunda com a prática. O seu "distanciamento" epistemológico da prática enquanto objeto de sua análise, deve dela "aproximá-lo" ao máximo. Quanto melhor faça esta operação tanto mais inteligência ganha da prática em análise e maior comunicabilidade exerce em torno da superação da ingenuidade pela rigorosidade (FREIRE, 1996, p. 43-44)
}

Nos primeiros anos do ensino fundamental, os saberes a serem dominados pelo professor pedagogo se organiza em conteúdos de forma distribuída. Sabe-se que a fragmentação do saber 
(a divisão do conhecimento em disciplinas / conteúdos específicos) se intensificou com o positivismo, e impactada por esta perspectiva, a educação passou a estruturar o seu currículo por meio de disciplinas isoladas como o que se tem hoje na educação escolar (ISKANDAR; LEAL, 2002).

Libâneo e Garrido em seu texto apontam que as transformações ocorridas na sociedade configuram desafios na educação pois, além de lidar com o ensino de português, matemática, geografia, história, etc., o professor deve estar atualizado sobre esses conteúdos e inovações metodológicas.

\begin{abstract}
O desenvolvimento profissional envolve formação inicial e contínua articuladas a um processo de valorização identitária e profissional dos professores. Identidade que é epistemológica, ou seja, que reconhece a docência como um campo de conhecimentos específicos configurados em quatro grandes conjuntos, a saber: conteúdos das diversas áreas do saber e do ensino, ou seja, das ciências humanas e naturais, da cultura e das artes; conteúdos didático-pedagógicos (diretamente relacionados ao campo da prática profissional); conteúdos relacionados a saberes pedagógicos mais amplos (do campo teórico da prática educacional) e conteúdos ligados à explicitação do sentido da existência humana (individual, sensibilidade pessoal e social) (LIBÂNEO; GARRIDO, 1999, p. 260).
\end{abstract}

Diante disso, compreendemos que fica explícito que o professor pedagogo que se almeja formar é aquele que domine os conhecimentos teórico-metodológicos, mas além disso, se espera um profissional capaz de dialogar com as individualidades e necessidades de ensino dos alunos. Um profissional que seja capaz de impulsionar o desenvolvimento a nível teórico, científico e humano.

\title{
Metodologia
}

Este artigo faz parte de uma pesquisa desenvolvida no Programa de Iniciação Científica Voluntária no período de outubro de 2018 a junho de 2019, na qual buscou-se analisar as percepções de profissionais da educação do município de Garanhuns (PE) acerca da formação inicial em Curso de Licenciatura em Pedagogia para a prática pedagógica na educação infantil e nos anos iniciais do ensino fundamental.

Foi desenvolvida uma pesquisa exploratória, que buscou "aumentar a compreensão de um fenômeno ainda pouco conhecido, ou de um problema de pesquisa ainda não perfeitamente delineado" (APPOLINÁRIO, 2011, p. 146). No que diz respeito a abordagem, esta foi predominantemente qualitativa, e quantitativa (SEVERINO, 2007). A técnica de coleta de dados utilizada foi o questionário que tratou de um "conjunto de questões, sistematicamente articuladas, que se destinam a levantar informações escritas por parte dos sujeitos pesquisados, 
com vistas a conhecer a opinião dos mesmos sobre os assuntos em estudo" (SEVERINO, 2007, p. 125).

Inicialmente, os questionários relativos ao ensino fundamental foram disponibilizados em meio digital, porém foi obtida apenas uma resposta dos professores. Dessa maneira, optouse por enviar as escolas os questionários em versão impressa. Estes foram entregues a Secretaria de Educação de Garanhuns que se responsabilizou por convocar os gestores das escolas do município para recolher os questionários na secretaria para assim distribuírem aos professores em cada escola. Ao todo foram entregues 159 questionários a Secretaria de Educação, porém foram retornados apenas 16 para a análise.

As perguntas do questionário foram organizadas em três dimensões que são: 1 Identificação; 2 - Formação inicial e complementar e 3 - Exercício profissional, prática docente e a formação nos Cursos de Licenciatura em Pedagogia.

Na dimensão 1 são apresentados os dados referentes ao sexo dos docentes entrevistados e a idade dos mesmos. Na dimensão 2 estão os dados referentes às graduações, instituições onde as mesmas foram realizadas e ano de conclusão. Da mesma forma, são apresentadas as respostas sobre a especialização de cada docente. Quanto a título de mestrado e doutorado nenhuma resposta foi registrada. Na dimensão 3 foram realizadas perguntas direcionadas ao tempo de exercício profissional dos docentes e perguntas a respeito do que foi ofertado nos cursos de formação, com base no que estabelece as Diretrizes Curriculares Nacionais para o Curso de Graduação em Pedagogia, licenciatura (2006).

Para identificação na análise e discussão de resultados, os docentes foram identificados com números de 1 a 16 antecedidos pela palavra professor (ex: professor 1, professor 2...), de acordo com o total de questionários recebidos. Nos resultados foram utilizadas falas de professores para reforçar as respostas dos mesmos, partindo da perspectiva da Análise de Conteúdo, conforme orientada por Bardin (2011).

\section{Resultados e discussão}

\section{Dimensão 1 - Identificação}

Foram recebidas 16 respostas, dessas apenas dois docentes não se identificaram. Dos 16 professores que responderam, 15 são do sexo feminino, sendo assim majoritário o número de respondentes do sexo feminino nesta pesquisa. 
Quanto a idade dos professores estas estão situadas nas seguintes faixas: 9 docentes entre 31 a 40 anos, 6 docentes entre 41 a 50 e apenas 1 docente na faixa de 21 a 30, compondo assim, um quadro docente de professores mais experientes em relação a idade.

Gráfico 1 - Idade

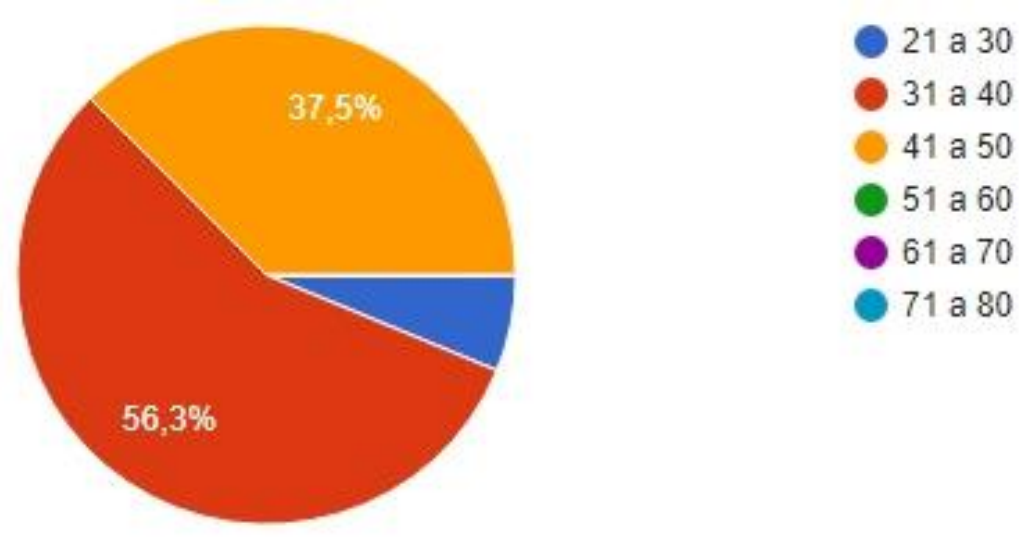

Fonte: Própria (2019)

\section{Dimensão 2 - Formação inicial e complementar}

Em relação às instituições em que foram realizadas as graduações, o maior número de respostas se concentram em 3 instituições de ensino como pode ser observado na tabela abaixo:

Tabela 1 - Instituições em que foram realizadas as graduações

\begin{tabular}{|c|c|c|c|c|c|c|c|}
\hline INSTITUIÇÕES & UPE & UFRPE & ULBRA & UFAL & INET & UNOPAR & UVA \\
\hline $\mathbf{N}^{\mathbf{0}}$ DOCENTES & 7 & 2 & 2 & 1 & 1 & 1 & 1 \\
\hline
\end{tabular}

Quanto às respostas, 7 dos docentes realizaram a graduação na Universidade de Pernambuco - UPE (Campus Garanhuns), 2 docentes realizaram na Universidade Federal Rural de Pernambuco - UFRPE e 2 docentes na Universidade Luterana do Brasil (ULBRA). Os demais professores realizaram suas graduações em outras instituições que são: Universidade Federal de Alagoas (UFAL), Instituto de Educação e Tecnologias (INET), Universidade Norte do Paraná (UNOPAR), Universidade Estadual Vale do Acaraú (UVA), estas com uma menção cada.

Quanto ao ano de conclusão dos cursos de formação inicial, os docentes concluíram seus cursos entre 2002 a 2016. Em relação aos cursos de especialização os mais citados foram 
psicopedagogia (clínica e institucional e institucional) com 7 respostas, os demais foram educação infantil, supervisão escolar e gestão pedagógica, EJA, coordenação pedagógica e supervisão escolar e história de Pernambuco.

Sobre as instituições nas quais foram realizadas as especializações, a mais citada pelos docentes foi a Universidade de Pernambuco - UPE (com 4 menções). Segue a tabela abaixo:

Tabela 2 - Instituições em que foram realizadas as especializações

\begin{tabular}{|c|c|c|c|c|c|c|c|c|}
\hline INSTITUIÇÕES & UPE & CESAC & FIP & CESA & UNIVERSO & FCE & $\begin{array}{l}\text { SÃO } \\
\text { LUÍS }\end{array}$ & UFRPE \\
\hline $\mathrm{N}^{\circ}$ DOCENTES & 4 & 1 & 1 & 1 & 1 & 1 & 1 & 1 \\
\hline
\end{tabular}

Fonte: Própria (2019)

As demais instituições tiveram uma menção cada, Centro de Ensino Superior Santa Cruz (CESAC), Faculdades Integradas de Patos (FIP), Centro de Ensino Superior de Arcoverde (CESA), Universidade Salgado de Oliveira (UNIVERSO), Faculdade Campos Elíseos (FCE), São Luís e a Universidade Federal Rural de Pernambuco (UFRPE). Os docentes concluíram suas especializações entre os anos de 2005 a 2019. Em relação a possuir título de mestrado ou doutorado, nenhuma resposta foi registrada.

\section{Dimensão 3 - Exercício profissional, prática docente e a formação nos Cursos de Licenciatura em Pedagogia}

Quanto ao exercício profissional, questionamos há quanto tempo os docentes atuam / atuaram nos anos iniciais do Ensino Fundamental, somando-se todas as suas experiências profissionais. O gráfico a seguir apresenta as respostas agrupadas.

Gráfico 2 - Tempo de atuação nos iniciais do Ensino Fundamental

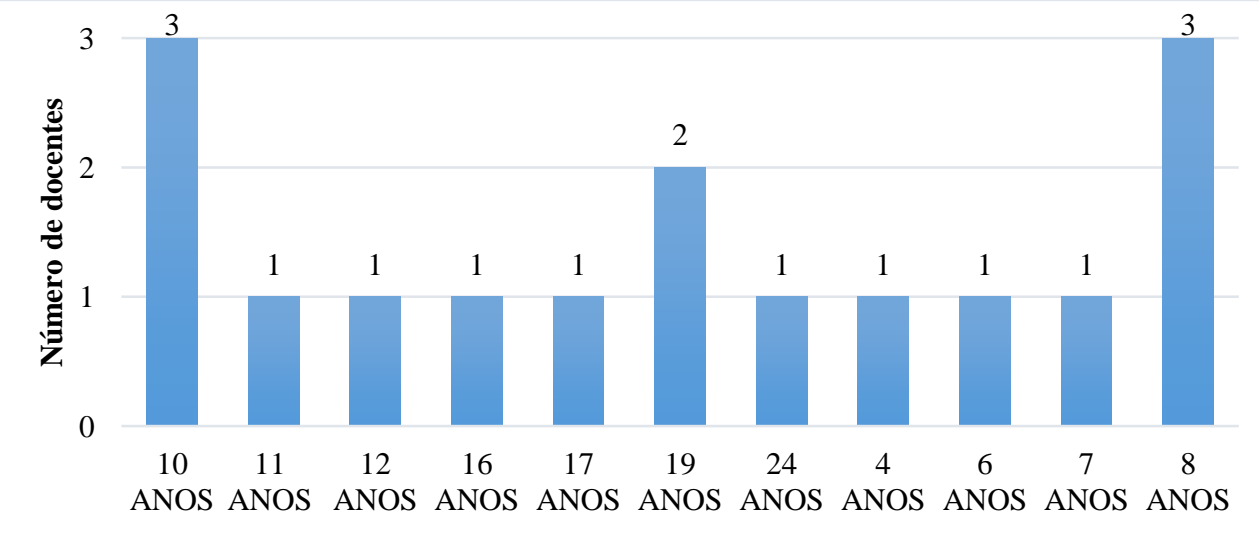

Fonte: Própria (2019) 
Como revelam os dados, pode-se verificar que metade dos docentes ( 8 deles) atua/atuou no Ensino Fundamental nas faixas de 8, 10 e 19 anos. De acordo com Tardif, o docente leva um determinado tempo para construir o seu perfil profissional.

“[...] é no início da carreira (de 1 a 5 anos) que os professores acumulam, ao que parece, sua experiência fundamental. [...] A experiência fundamental tende a se transformar, em seguida, numa maneira pessoal de ensinar, em macetes da profissão, em habitus, em traços da personalidade profissional (TARDIF, 2010, p. 51).

Assim, Tardif aponta que são nos primeiros 5 anos que o docente constrói seu perfil profissional (maneira pessoal de ensinar) mediante o acúmulo de experiências na carreira docente. Compreendemos, portanto, que os docentes já construíram os seus perfis profissionais mediante o tempo de atuação de cada um.

Perguntamos se o curso os preparou "para exercer funções de magistério [...] nos anos iniciais do Ensino Fundamental” (Diretrizes Curriculares Nacionais para o Curso de Graduação em Pedagogia, licenciatura, 2006, Art. $4^{\circ}$ ). Metade dos docentes afirmam concordar totalmente que os cursos de graduação os preparou para exercer funções do magistério. A segunda maior parcela corresponde aos docentes que concordam parcialmente e uma terceira parcela discordou parcialmente.

Gráfico 3 - Formação inicial x preparação para exercer funções de magistério nos anos iniciais do Ensino Fundamental
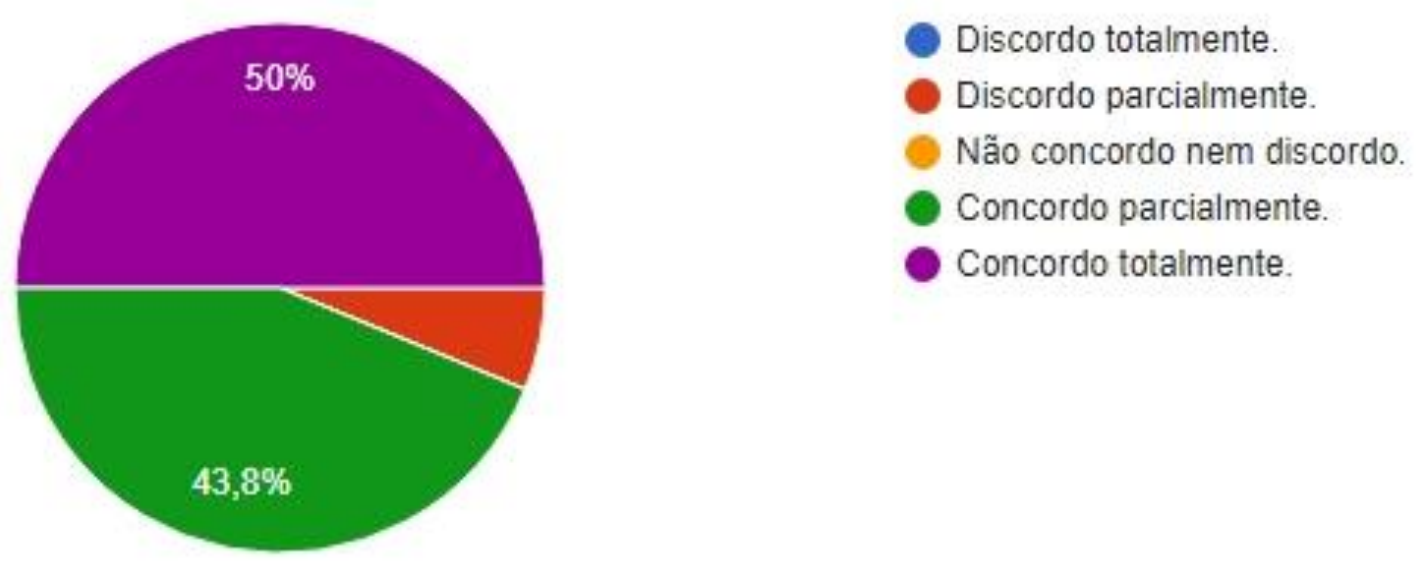

Fonte: Própria (2019)

As principais justificativas dos professores para esses percentuais dizem respeito a necessidade de uma melhor articulação entre teoria e prática, insuficiência das disciplinas do curso para abordar as diferentes temáticas da educação, dentre elas foram apontadas a pouca 
atenção em relação ao estudo relacionado a Educação infantil e a pouca atenção para o campo dos problemas de aprendizagem.

No que se refere a necessidade da articulação entre a teoria e prática:

Quanto à relação teoria e prática compreende-se que são realidades distintas intimamente imbricadas. Entende-se que acreditar que a teoria ou a prática por si só seriam capazes de transformar a realidade tem sido um equívoco repetido ao longo da história da formação de professores, tanto por meio de processos formativos, que apenas trabalham conhecimentos teóricos, quanto por meio daqueles que priorizam aspectos pragmáticos. (SOMMERHALDER; FERNANDES; DUARTE; SANTOS, 2016, p. 281).

Embora sejam diferentes, a teoria e a prática são interdependentes e por isso devem estar articuladas na formação docente, pois de maneira isolada não são suficientes para que se possam desenvolver práticas que atendam a realidade.

Questionamos se o curso preparou os docentes para "trabalhar na promoção da aprendizagem e do desenvolvimento de sujeitos em diferentes fases do desenvolvimento humano nas etapas e modalidades de educação básica" (DCN Pedagogia, 2006, Art. $5^{\circ}$, inciso IV; 2015, Art. $8^{\circ}$, inciso III).

Gráfico 4 - Trabalhar na promoção da aprendizagem e do desenvolvimento de sujeitos em diferentes fases do desenvolvimento humano nas etapas e modalidades de educação básica
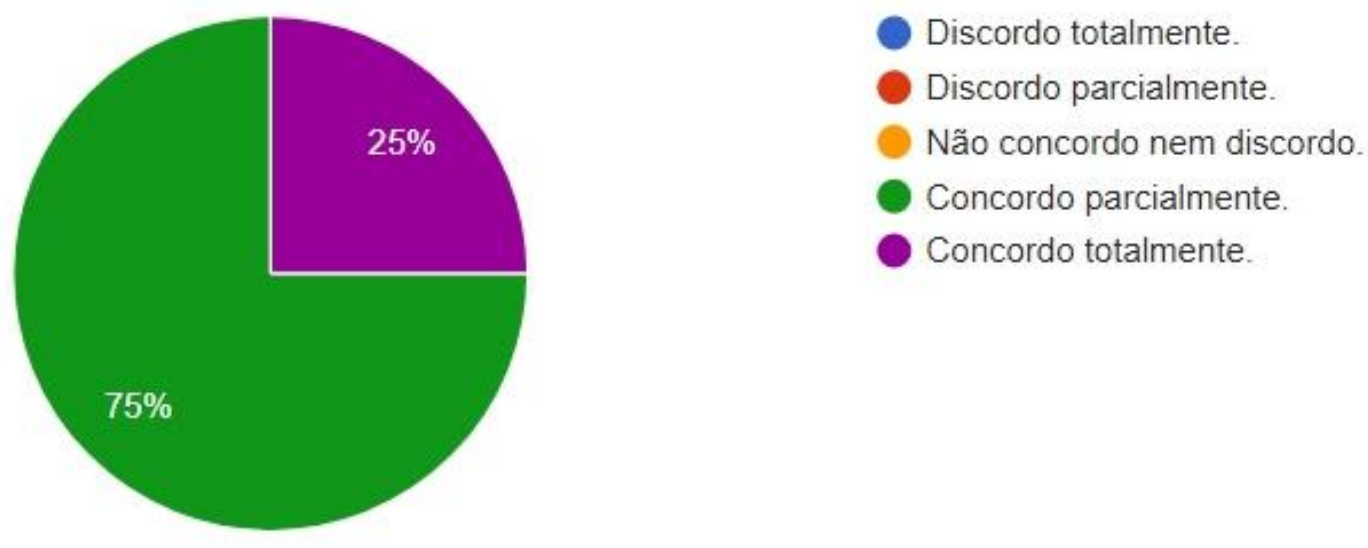

Fonte: Própria (2019)

De acordo com os dados é possível afirmar que todos os docentes concordam com essa afirmação, sendo que do total há uma parcela maior de $75 \%$ que concorda de maneira parcial e uma menor parcela que concorda totalmente.

Dentre as justificativas para tal resultado as mais apontadas foram a necessidade de maior relação entre teoria e prática nos cursos de formação (SOMMERHALDER; FERNANDES; DUARTE; SANTOS, 2016) como já apontado na questão anterior. Além disso, 
se pontua a necessidade de maior atenção a questão curricular no que diz respeito a oferta das disciplinas direcionadas à EJA e Educação Especial, pois segundo alguns docentes estas foram insuficientes.

Outro ponto específico mencionado nas justificativas dos professores para a pergunta em questão se relaciona a necessidade de aprender na prática. Quanto a isso, ao falar sobre saberes docentes Tardif explica:

[...] os próprios professores, no exercício de suas funções e na prática de sua profissão, desenvolvem saberes específicos, baseados em seu trabalho cotidiano e no conhecimento de seu meio. Esses saberes brotam da experiência e são por ela validados. Eles incorporam-se à experiência individual e coletiva sob a forma de habitus e de habilidades, de saber-fazer e de saber-ser. Podemos chamá-los de saberes experienciais ou práticos (TARDIF, 2010, p. 38-39).

É no ofício diário das suas funções que o docente se atém a sua profissão, ou seja, na prática. Esse é um saber docente que corresponde aos chamados saberes da experiência e também por meio desses o docente conduz sua prática, tal saber funciona como um filtro para os demais saberes (curriculares, pedagógicos, etc.) mobilizados pelo professor.

Em concordância com a necessidade de um trabalho de formação docente que também considere a importância da prática, Nóvoa defende que a formação de professores seja construída dentro da profissão docente que deve assumir "uma forte componente práxica, centrada na aprendizagem dos alunos e no estudo de casos concretos, tendo como referência o trabalho escolar" (NÓVOA, 2009, p. 4).

Como pontos positivos o professor 9 e professor 14, apontaram que "o curso proporcionou compreender como as pessoas aprendem, o que aprendem e como utilizar recursos que favoreçam essa aprendizagem”, "o desenvolvimento e uma forma de transmitir a aprendizagem significativa".

Em seguida questionamos se o curso preparou os docentes para "reconhecer e respeitar as manifestações e necessidades físicas, cognitivas, emocionais, afetivas dos educandos nas suas relações individuais e coletivas" (DCN Pedagogia, 2006, Art. 5, inciso V). O gráfico adiante apresenta um recorte das respostas das professoras. 
Gráfico 5 - Reconhecer e respeitar as manifestações e necessidades físicas, cognitivas, emocionais, afetivas dos educandos nas suas relações individuais e coletivas
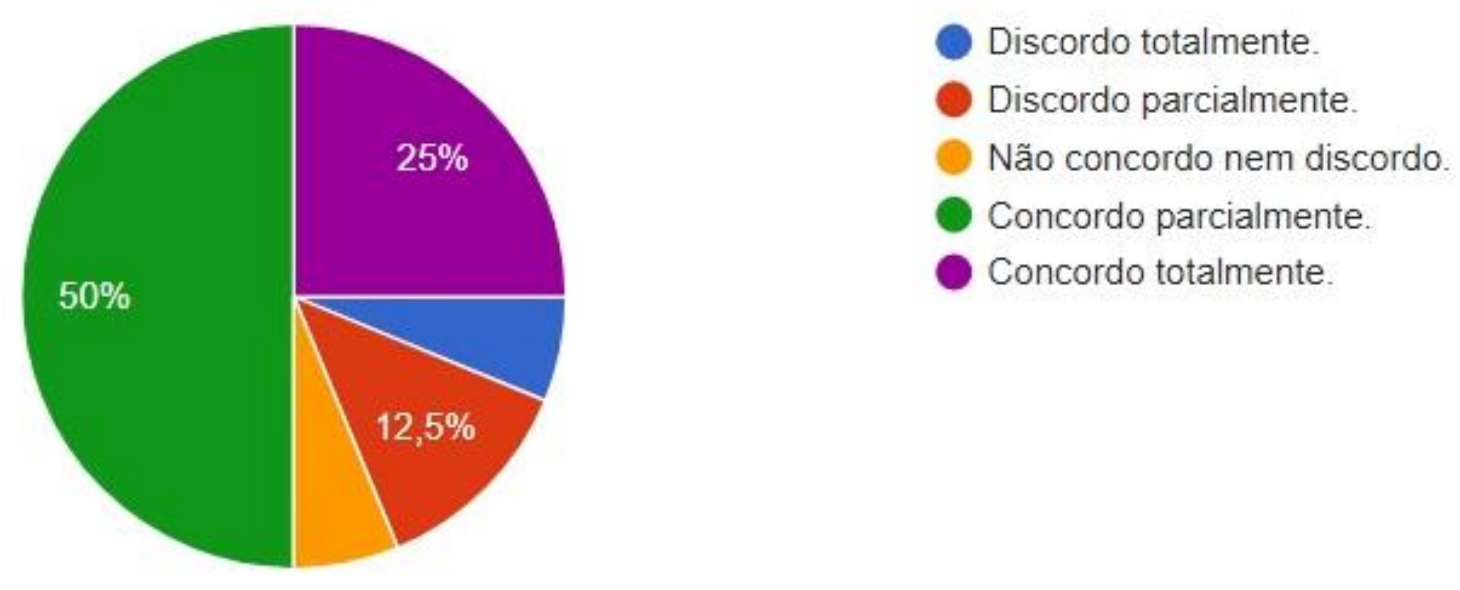

Fonte: Própria (2019)

Dentre as justificativas apresentadas pelos respondentes as principais foram a distância da realidade em relação a prática e a necessidade de se ter um curso que oferte mais disciplinas voltadas para a prática como os "estágios" assim como mencionou o professor 3, além de outras atividades que trabalhem na perspectiva da realização de prática.

O estágio curricular supervisionado é concebido, nesta discussão, como um dos elementos fundantes dos projetos pedagógicos de formação para a docência, sendo definido como espaço/momento de exercício preparatório sui generis das práticas a serem adotadas, na atuação profissional (SOUZA; RODRIGUES; GOMES, 2016, p. 3)

Assim, compreende-se que o estágio curricular supervisionado é um momento formador para os futuros docentes sendo este preparatório para prática. Também os professores 8 e 16 apontam que na "[...] prática no dia-a-dia é que vamos aprendendo". Ao chamar atenção para a aprendizagem na prática cotidiana docente, destaca-se a importância dos saberes da experiência (TARDIF, 2010). Na visão de alguns respondentes, é somente no contato com o campo de atuação profissional que se aprende a identificar e reconhecer as necessidades dos estudantes nas esferas físicas, emocionais e cognitivas, tanto de maneira individual como coletiva.

Também questionamos se curso preparou os docentes para ensinar Língua Portuguesa, Matemática, Ciências, História, Geografia, Artes e Educação Física, de forma interdisciplinar e adequada para as diferentes fases do desenvolvimento humano (DCN Pedagogia, 2006, Art. $5^{\circ}$, inciso VI). 
Gráfico 6 - Ensinar Língua Portuguesa, Matemática, Ciências, História, Geografia, Artes e Educação Física, de forma interdisciplinar e adequada para as diferentes fases do desenvolvimento humano

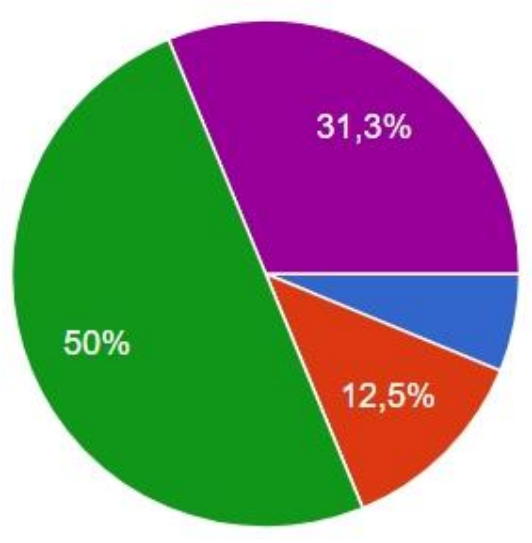

Discordo totalmente.

Discordo parcialmente.

Não concordo nem discordo.

Concordo parcialmente.

Concordo totalmente.

Fonte: Própria (2019)

As respostas dos docentes novamente se direcionaram a questão da prática enfatizando a insuficiência e superficialidade dos cursos no que diz respeito a trabalhar tais disciplinas e novamente a necessidade da prática constante, assim para isso o professor 7 sugere a oferta de "[...] uma disciplina que o foco seja a prática”.

Os docentes também mencionam em suas respostas a importância do exercício diário da profissão para trabalhar com o conjunto das disciplinas, isso pode ser verificado nas respostas do professor 9 e 13 respectivamente: "[...] por mais que uma instituição de ensino lhe prepare para o mercado de trabalho, só será consolidada totalmente na prática ao exercer suas atividades docentes", "aprendi na prática após me formar e já exercendo a docência", ou seja, os saberes da experiência (TARDIF, 2010) são fundamentais neste quesito.

Uma outra questão levantada pelos docentes diz respeito a interdisciplinaridade. Para uma parcela destes os trabalhos realizados por meio interdisciplinar nos cursos, embora que de maneira insuficiente e superficial, contribuíram com o preparo para trabalhar tais disciplinas, dando assim uma noção do trabalho interdisciplinar.

\section{Conclusões}

Foi possível concluir com a realização dessa pesquisa que a percepção dos professores acerca da formação inicial nos cursos de graduação tem contribuído para o exercício da prática docente, mas ainda os cursos têm deixado várias lacunas formativas como foi possível apreender nas respostas dos docentes.

Os professores também apontam nas respostas dos questionários que para o exercício da 
prática docente nos anos iniciais do Ensino Fundamental, os mesmos devem dominar um extenso repertório saberes que em sua totalidade só se realizam na prática diária da sala de aula. Estes devem dominar saberes diferentes entre si para desenvolver suas práticas, porém dentro do leque de saberes requisitados pelos professores foi possível ratificar que há um consenso entre os docentes quanto a necessidade de ênfase nas atividades práticas nos cursos de formação inicial, ou seja, de se trabalhar com a oferta de mais conteúdos/atividades práticas já desde de os cursos de graduação. A necessidade do saber prático (experiencial) foi o mais mencionado pelos professores em suas respostas, marcando assim a sua grande importância para a formação.

Por fim, é importante frisar que essa pesquisa apresentou as percepções dos próprios professores que atuam na educação básica, mas especificamente nos anos iniciais do Ensino Fundamental, trazendo as visões dos docentes em relação aos seus cursos de formação inicial e a prática docente, ou seja, o que apresentamos aqui não foi a visão teórica da academia, mas sim as visões docentes advindas das realidades diárias da educação escolar. Desta maneira, esperamos que essa pesquisa contribua positivamente para a reflexão acerca da formação de professores nos cursos de graduação em Pedagogia.

\section{Referências}

APPOLINÁRIO, F. Dicionário de metodologia científica. São Paulo: Atlas, 2011.

BARDIN, Lawrence. A análise de conteúdo. São Paulo: Edições 70, 2011.

BRASIL. Resolução CNE/CP no 1, de 15 de maio de 2006. Institui Diretrizes Curriculares Nacionais para o Curso de Graduação em Pedagogia, licenciatura. Disponível: http://portal.mec.gov.br/cne/arquivos/pdf/rcp01_06.pdf>. Acesso em: 30 maio 2018.

FREIRE, P; SHOR, I. Medo e Ousadia: o cotidiano do professor. Rio de Janeiro: Paz e Terra, 1987.

FREIRE, P; TORRES, C. Educação na Cidade. São Paulo: Cortez, 1991.

FREIRE, P. Pedagogia da autonomia: saberes necessários à prática educativa. Rio de Janeiro: Paz e Terra, 1996.

ISKANDAR, J. I; LEAL, M.R. Sobre positivismo e educação. Revista Diálogo Educacional, v. 3, n. 7, p. 89-94, 2002. Disponível em: http://www2.pucpr.br/reol/index.php/DIALOGO?dd 1=654\&dd99=view Acesso em: 03 fev. 2009. 
LIBÂNEO, J. C; PIMENTA, S. G. Formação de profissionais da educação: visão crítica e perspectiva de mudança. Educação \& Sociedade. v. 20, n. 68, p. 239-277, 1999. Disponível em: http://www.scielo.br/pdf/\%0D/es/v20n68/a13v2068.pdf. Acesso em: 10 nov. 2018.

NÓVOA, A. Para uma formação de professores construída dentro da profissão. 2009. Disponível em: http://www.revistaeducacion.educacion.es/re350/re350_09por.pdf. Acesso em: 14 maio. 2019.

PIMENTA, S. G. Didática e formação de professores. São Paulo: Cortez, 1997.

SEVERINO, A. J. Metodologia do trabalho científico. 23a ed. rev. atual. São Paulo: Cortez, 2007.

SOUZA, D. B; RODRIGUES, S. A; GOMES, A. A. Formação inicial e saberes necessários para a docência na educação infantil: o papel do estágio supervisionado. Educere et Educare, v. 11, n. 23, 2016. Disponível em: http://e-revista.unioeste.br/index.php/educereeteducare/article/view/ 13632. Acesso em: 10 nov. 2018.

SOMMERHALDER, A; FERNANDES, J. R; DUARTE, C. T; SANTOS, C. M. Estágio curricular supervisionado e a relação teoria e prática: sentidos construídos por licenciandos em Pedagogia. Revista Educação: Teoria e Prática, v. 26, n. 52, 2016. Disponível em: http://webcache.googleusercontent.com/search?q=cache:927oouU3xa4J:www.periodicos.rc.bib lioteca.unesp.br/index.php/educacao/article/download/8210/7668/+\&cd=3\&hl=ptBR\&ct=clnk $\& \mathrm{gl}=$ br\&client=opera. Acesso em: 10 nov. 2018.

TARDIF, M. Saberes docentes e formação profissional. $4^{\mathrm{a}}$ ed. Rio de Janeiro: Vozes, 2010. 